\section{SAT0117 PROGLUMETACIN AND THE PREVENTION OF ECTOPIC OSSIFICATION FOLLOWING TOTAL HIP REPLACEMENT}

${ }^{1}$ KK Förster, ${ }^{2} \mathrm{~A}$ Thiede, ${ }^{2} \mathrm{~J}$ Haasters. ${ }^{1}$ Department of Clinical Research, Opfermann Arzneimittel GmbH, Wiehl, Germany; ${ }^{2}$ Orthopaedic Department, Ostseeklinik (Baltic Sea (linic), Damp, Germany

10.1136/annrheumdis-2001.513

Background Ectopic ossifications (EO) following total hip replacement are possible and known post-operative complications, developing in about $60 \%$ of patients during the first $4-12$ weeks after implantation. There is no treatment but surgery, therefore preventive measures are considered to be indispensible. Proven and sufficient measures to prevent EO are radiation treatment or treatment with non-steroidal anti-inflammatory drugs (NSAIDs). These measures are able to reduce EO to occur in about $10 \%$ of prophylactically treated patients.

Objectives The objective of this retrospective study was to evaluate our practice of treating patients postoperatively with the NSAID proglumetacin - a molecular combination of indomethacin with the gastroprotective substance proglumid - and to compare the success rate with that of competitive preventive treatments.

Methods During the years from 1995 to 1997 there were 560 patients in our orthopaedic department who underwent total hip replacement, in most of them because of osteoarthritis of the hip. Other reasons for surgery were femur head necrosis, rheumatoid arthritis, femoral neck fractures or loosening of an already existing hip endoprosthesis. Immediately after surgery, 2 weeks and again 2 months later, and, if possible, also 6 months later, control X-rays were performed. Signs of ossification were objectified using the Brooker classification.

Results 545 of these patients (573 women, 188 men; mean age: $66.8 \pm 9.7$ years; body weight: $75.6 \pm 13.2 \mathrm{~kg}$; body length: $167.3 \pm 8.5 \mathrm{~cm}$ ) were postoperatively treated for 3 weeks with proglumetacin. X-ray films of all patients after surgery showed no ossification, just as after 2 weeks the films of 506, after 2 months of 473, and after 6 months of 263 (of 329 re-examined) patients. Clinically not relevant ossifications (class I or II according to Brooker) were seen after 2 weeks in 37 patients $(6.8 \%)$, after 2 months in 57 patients (10.5\%) and after 6 months in 65 $(11.9 \%)$ patients. Of all patients treated for at least one week no one $(0.0 \%)$ showed a clinically relevant ossification (class III or IV). Two patients showing class III ossification were prophylactically treated only for 6 and 4 days, respectively. Concerning EO occurrence, in our patients there was no correlation with gender, kind of prosthesis or anaesthesia, duration of hip disease, or risk factors like already performed total hip replacement and diabetes mellitus, respectively.

Concerning safety only 43 patients (7.9\%) complained of minor or increasing gastric adverse drug reactions, requiring additional gastroprotective drug therapy or even stop of treatment.

Conclusion In conclusion, the non-steroidal anti-inflammatory drug proglumetacin is very safe and at least as effective as other preventive measures and very safe. In our view, proglumetacin therefore represents a favourable and economic alternative treatment.

\section{REFERENCES}

1 Brooker AF, et al. Ectopic ossification following hip replacement: incidence and a method of classification. J Bone Joint Surg Am. 1973;55:1629-32

2 Eulert J, Knelles D, Barthel T. Heterotope Ossifikationen. Orthopäde 1997;26:399-406
3 Förster KK, Haasters J, Schmid K, Thiede A. Prevention of heterotopic ossifications after total hip replacement with a non-steroidal anti-inflammatory drug (abstract). Eur J Clin Pharmacol. 1997:A11

4 De Pouvourville G. Evaluating the real cost of NSAID therapy; "shadow costs" relating to the treatment of gastrointestinal side effects. $\mathrm{Br} / \mathrm{Med}$ Econ. 1992;5:45-50

\section{Cell receptor-ligand interaction signalling and activation}

\section{AB0008 CERULOPLASMIN, TRANSFERRIN AND INTRACELLULAR ADHESION MOLECULE-1 IN PATIENTS WITH RHEUMATOID ARTHRITIS}

${ }^{1} \mathrm{~S}$ Cogalgil, ${ }^{1} \mathrm{~K}$ Yildirim, ${ }^{2} \mathrm{~S}$ Tayli, ${ }^{2} \mathrm{~F}$ Akcay. ${ }^{1}$ Physical Therapy and Rehabilitation;

${ }^{2}$ Biochemistry, Arastirma Hospital, Erzurum, Turkey

10.1136/annrheumdis-2001.514

\section{Background}

Objectives We studied serum levels of soluble intercellular adhesion molecule-1 (sICAM-1), ceruloplasmin (CP) and transferrin (Tf) and investigated the correlation of these parameters with the disease activity.

Methods Serum sICAM-1 levels were determined with sandwich enzime-linked immunosorbent assay (ELISA) in sera from 42 patients with RA and in 30 healthy controls. Erythtrocyte sedimentation rate (ESR) was determined according to the Westhergen method and C-reactive protein (CRP), CP and Tf by nephelometric method. Disease activity was assessed by disease activity criterias.

Results Although decreased serum Tf level, serum levels of sICAM-1 and CP were significantly higher in patients with RA than in healthy controls. It was found that sICAM-1 had a negative correlation with Tf $(\mathrm{r}=? 0.47, \mathrm{p}<0.01)$ and a positive correlation with $\mathrm{CP}(\mathrm{r}=0.49, \mathrm{p}<0.001)$. There was a weak but statistically significant positive correlation between sICAM levels with Ritche articular index (RAI) score and CRP ( $\mathrm{r}=0.32, \mathrm{p}<$ $0.05 ; \mathrm{r}=0.44, \mathrm{p}<0.01$, respectively), whereas no significant correlation was observed between sICAM-1 levels with ESR, age and disease duration. There was no correlation between values of CRP, RAI and ESR with serum CP and Tf.

Conclusion These data show that the decreases in serum CP and Tf levels and increases in sICAM-1, ESR and CRP levels are present in RA, and that the decrease in serum CP and Tf levels in RA might be due to increased sICAM-1, and increased levels of sICAM-1 and correlations with other parameters may be a significant and novel marker for evaluating the disease status and the activity of RA.

\section{OP0001 REDOX-SENSITIVE CHANGES IN CONFORMATION AND CELLULAR LOCALIZATION OF LAT AND DOWNSTREAM TCR SIGNALLING LEAD TO HYPORESPONSIVENESS OF SYNOVIAL FLUID T CELLS IN RHEUMATOID ARTHRITIS}

SI Gringhuis, PH Remans, EA Papendrecht-van der Voort, A Leow, EN Levarht, FC Breedveld, CL Verweij. Department of Rheumatolgy, Leiden University Medical Center, Leiden, The Netherlands

\subsection{6/annrheumdis-2001.515}

Background In rheumatoid arthritis (RA), the synovial fluid (SF) $\mathrm{T}$ lymphocytes present in the inflamed joints, display 